\title{
Anestesia para cirugía fetal: experiencia en un hospital público de Santiago de Chile y revisión de la literatura
}

\author{
Carla Maldonado, Daniel Riquelme², Pedro Torres²
}

Introducción: La cirugía fetal es un campo que ha experimentado un gran progreso en las últimas décadas. El avance en las técnicas de diagnóstico prenatal ha permitido tratamiento de patologías fetales inutero, de modo que actualmente es posible modificar la historia natural de determinadas alteraciones en el desarrollo del feto evitando secuelas en el recién nacido y en su posterior desarrollo en la vida extrauterina. El manejo perioperatorio de la cirugía fetal precisa de un equipo multidisciplinario, constituyendo un desafío para el anestesiólogo mantener la homeostasis de la madre y el feto.

Objetivo: Describir las características y técnica anestésica utilizada en una serie de cirugías fetales realizadas en un hospital público de Santiago de Chile entre abril de 2015 y agosto de 2018. Además se realiza una revisión sistemática de la literatura al respecto.

Material y Métodos: Análisis de fichas clínicas de pacientes cursando embarazo con indicación de cirugía fetal. Se registraron características de la madre, diagnóstico fetal, tipo de procedimiento, técnica anestésica y complicaciones maternas.

Resultados: Se obtuvieron datos de 48 pacientes que se sometieron a cirugía por indicación fetal. En 1 embarazo gemelar se realizó 2 cirugías durante el embarazo. En total fueron 49 procedimientos. La edad promedio materna fue de $28,9 \pm 6$ años. La edad gestacional promedio fue 19,8 semanas \pm 2 días. Todas las cirugías fueron realizadas durante el segundo trimestre de embarazo. 43 cirugías fueron realizadas en embarazos gemelares, de éstos 40 embarazos monocoriales biamnióticos y 3 embarazos gemela- res triples. En los embarazos gemelares, 42 cirugías fueron por síndrome de transfusión feto-fetal (STFF) y 1 por secuencia TRAP. Cinco pacientes tuvieron indicación quirúrgica por otras causas, entre ellas brida amniótica, 2 malformaciones urinarias y 2 malformaciones pulmonares. Todos los procedimientos fueron realizados mediante fetoscopía. En cuanto a la técnica anestésica, 1 cirugía fue realizada con anestesia general, 28 con anestesia espinal y 20 con anestesia espinal-epidural combinada. 47 procedimientos fueron con monitorización estándar y en 2 se agregó línea arterial. En 35 procedimientos se utilizó remifentanil TCI para sedación materna e inmovilización fetal. De las complicaciones maternas perioperatorias, en 1 procedimiento fetoscópico con anestesia neuroaxial por STFF al día siguiente la madre presentó hemoperitoneo que requirió laparotomía exploradora con anestesia general y posteriormente presentó falla respiratoria que requirió ventilación mecánica no invasiva. En una fetoscopía durante coagulación de comunicaciones arteriovenosas se produjo sangrado profuso que impidió terminar el procedimiento y posteriormente se desencadenó parto pretérmino. Una madre requirió parche de sangre por cefalea post punción dural. Una madre presentó bacteriemia por Eschericia coli en el puerperio.

Conclusiones: El avance en técnicas quirúrgicas que permiten intervenir anomalías fetales han posibilitado cambiar el pronóstico de ciertas enfermedades susceptibles de tratamiento en la vida intrauterina. Estos procedimientos no se encuentran exentos de complicaciones. 